Teknik, 38 (1), 2017, 49-57

\title{
Kecepatan Putaran Poros Pada Mesin Pembuat Pakan Pelet Berpenggerak Kayuh Sepeda
}

\author{
Adi Nugroho*, Arif Wibowonoto \\ Program Studi Teknik Industri, Fakultas Teknik, Universitas Putera Batam, \\ Jalan R. Soeprapto Muka Kuning, Batam, Indonesia
}

\begin{abstract}
Abstrak
Kajian penelitian ini dilatar belakangi adannya inkonsistensi gaya yang dihasilkan oleh tenaga manusia untuk menggerakkan alat penggiling yang terdapat pada mesin pembuat pakan pelet sederhana. Salah satu usaha yang dapat dilakukan adalah dengan menggunakan sproket sepeda yang berfungsi mentransmisikan gaya ke dalam putaran sepeda sehingga nantinya dapat mencapai tingkatan putaran (rpm) yang diinginkan. Untuk dapat mencapai kondisi tersebut, dibutuhkan ukuran sproket yang tepat melalui pengujian kecepatan putaran di masing-masing alternatif ukuran. Penelitian ini bertujuan untuk mengetahui berapakah ukuran sproket yang dapat menghasilkan kecepatan putaran poros mesin pembuat pelet sebesar 626 rpm dari kecepatan putaran kayuhan sepeda sebesar yang hanya mencapai 60-100 rpm. Metode pengumpulan data yang digunakan dalam penelitian adalah observasi dan literatur. Variabel yang menjadi parameter pengukuran dalam penelitian ini adalah ukuran sproket dan kecepatan putaran poros (rpm). Analisis data dilakukan dengan menggunakan teknik analisis parametrik. Hasil penelitian menunjukkan bahwa untuk mendapatkan kecepatan putaran poros mesin pembuat pelet sebesar 626 rpm diperlukan kecepatan kayuhan sebesar 54 rpm saat $N_{2}(18 \mathrm{~T}), 63 \mathrm{rpm}$ saat $N_{2}(21 \mathrm{~T})$, dan $72 \mathrm{rpm}$ saat $N_{2}(24 \mathrm{~T})$ sedangkan ukuran sproketnya masing-masing sebesar $N_{1}(34 T), N_{2}(18 T, 21 T, 24 T), N_{3}(42 T), N_{4}(11 T), N_{5}$ (24 T) dan $N_{6}(15 T)$.
\end{abstract}

Kata kunci: mesin pembuat pelet; poros; rasio kecepatan; sproket

\begin{abstract}
[Title: Axis Spin Speed on Bicycle Pedal - driven Pellets Machine] The background of this study was the inconsistency of human power to run a simple pellets spinner machine. One of the options to do this is by using bicycle sprocket to transmit power until it reaches the expected speed. Particular size of sprocket is needed to gain the intended speed. To determine the axact size several test were needed, by combining various the speed rotation and sprocket size. This research aimed to determine the exact size of sprocket in order to reach $626 \mathrm{rpm}$. Variables used were spocket size and axis spin speed (rpm). Data collecting methods used were literature study and observation. Data analysis was done using parametric analysis technique. The result showed that to reach sprocket speed of $626 \mathrm{rpm}$, required $54 \mathrm{rpm}$ at $N_{2}(18 \mathrm{~T}), 63 \mathrm{rpm}$ at $N_{2}(21 \mathrm{~T})$, and $72 \mathrm{rpm}$ at $N_{2}(24 \mathrm{~T})$ to reach $626 \mathrm{rpm}$. And the size of spockets are $N_{1}(34 T), N_{2}(18 T, 21 T, 24 T), N_{3}(42 T), N_{4}(11 T), N_{5}(24 T)$ and $N_{6}(15 T)$.
\end{abstract}

Keywords: pellets machine; axis; speed ratio; sprocket

\section{Pendahuluan}

Biaya operasional untuk pakan dalam budidaya lele mencapai $60 \%$ dari total biaya produksinya (Muliantara, 2012). Salah satu usaha yang telah dilakukan untuk menghemat biaya produksi ini adalah dengan merancang alat produksi yang mampu menghasilkan produk pakan pelet. Beberapa rancangan alat produksi hasil penelitian yang telah dilakukan diantaranya adalah alat dengan kapasitas $25,85 \mathrm{~kg} / \mathrm{jam}$ menggunakan motor listrik $1 \mathrm{Hp}$ sebagai tenaga penggerak (Syahputra, 2010), alat pembuat pakan pelet dengan kapasitas 100-150 kg/jam menggunakan mesin

\footnotetext{
${ }^{*}$ Penulis Korespondensi.

E-mail: aaddinugroho@gmail.com
}

diesel sebagai tenaga penggeraknya (Tjahjanti dkk., 2013) dan penggunaan sistem transmisi sabuk-puli dengan kapasitas produksi mencapai 27,99 Kg/jam melalui motor listrik $1 \mathrm{Hp}$ (Leksono, Setiyo, Tika, 2014).

Ketiga model alat tersebut menggunakan penggerak utama berupa motor listrik dan mesin diesel yang membutuhkan tambahan biaya operasional, yakni tagihan listrik ataupun pembelian bahan bakar. Berangkat dari permasalahan tersebut, penelitian ini dimaksudkan untuk merancang mesin pembuat pakan pelet menggunakan penggerak kayuh sepeda. Penerapan teknik ini bukan tanpa masalah, salah satunya adalah sumber tenaga yang tidak konstan karena sumber tenaga berasal dari tenaga manusia yang 
akan mengalami naik turun (fluktuasi) tergantung pada kondisi fisik yang sedang dialami.

Penggunaan sistem sabuk-puli untuk menurunkan putaran motor listrik dengan cara mengatur ukuran dari puli pada poros sehingga didapatkan putaran yang konstan sebesar $626 \mathrm{rpm}$ pada alat pencetak yang telah dilakukan uji coba dalam beberapa penelitian (Leksono, 2011). Teknik tersebut bertentangan dengan sistem penggerak sepeda yang menerapkan sistem transmisi rantai-sproket yang hanya mampu mendapatkan putaran penggerak sebesar 60-100 rpm (Fujita dkk., 2014). Beberapa dasar teori yang menjelaskan penggunaan kayuh sepeda sebagai pengerak diantaranya:

1. Pemanfaatan kayuh sepeda sebagai penggerak dari pompa air dengan desain pelek pada roda belakang dari sepeda digunakan sebagai pengganti puli dan dihubungkan menggunakan sabuk ke puli (transmisi sabuk-puli) pada poros pompa (Garg, dkk., 2013).

2. Pemanfaatan kayuh sepeda sebagai penggerak kompresor dan pompa air dengan menggunakan gabungan sistem transmisi rantai dan transmisi roda gigi (Gehlot dkk., 2015).

3. Desain alat yang dibuat yaitu roda belakang dari sepeda langsung dihubungkan dengan poros dari pompa sentrifugal (Sreejith, dkk., 2014).

4. Desain alat yang dibuat adalah ada dua sistem transmisi rantai sproket dimana pada poros sproket terakhir dipasangkan engkol yang terhubung ke sebuah "connecting rod" untuk merubah putaran menjadi gerakan maju-mundur pada gergaji besi (Subash dkk., 2014).

Dari beberapa penelitian yang telah dilakukan sebelumnya, dapat dijelaskan bahwa penggunaan sproket sebagai salah satu media transmisi penggerak dapat membantu kerja dari suatu alat. Namun penggunaan media ini bukan tanpa masalah. Adanya inkonsistensi gaya yang dihasilkan oleh sumber tenaga yang digunakan beberapa alat seperti kayuh sepeda menyebabkan gaya yang ditransmisikan menjadi tidak teratur. Kondisi ini dapat mengakibatkan media penggiling yang bertugas untuk mencetak material pakan dalam bentuk padat menjadi tidak maksimal. Kondisi ini ditunjukan melalui hasil campuran material pakan yang tidak merata (lengket) pada saat masuk didalam cetakan. Selain itu jika putarannya terlalu besar maka juga dapat mengakibatkan material yang ada dalam alat penggiling akan keluar dari tempatnya. Kondisi ini disiasati dengan menerapkan sistem sabuk-puli yang bertujuan untuk menurunkan putaran motor listrik dengan cara mengatur ukuran dari puli pada poros sehingga didapatkan putaran yang konstan sebesar $626 \mathrm{rpm}$ (Leksono, 2011). Melalui gagasan tersebut, penelitian ini mencoba untuk menerapkan teknik kerja sabuk-puli pada alat pembuat pakan pelet yang sumber tenaganya berasal dari kayuh sepeda. Perbedaannya terletak pada usaha untuk mendapatkan kecepatan putaran poros yang konstan dengan memodifikasi ukuran sproket sehingga diharapkan dapat diperoleh informasi kemampuan dari masingmasing alternatif ukuran.

\section{Bahan dan Metode}

Alat yang menjadi kajian penelitian adalah mesin pelet, dengan pokok bahasan berupa optimasi kecepatan putaran pada poros alat pencetak pelet. Alat pencetak pelet ini menggunakan penggerak kayuh sepeda melalui beberapa rangkaian transmisi rantai-sproket yang digerakkan secara manual melalui media kayuh yang berasal dari kaki manusia (Gambar 1). Rencana deskripsi alat yang akan dirancang sebagai berikut:

1. Terdapat engkol kayuh sepeda yang merupakan satu poros dengan sebuah sproket dan dihubungkan ke grup sproket pertama yang terdiri dari tiga unit sproket yang berbeda jumlah giginya pada poros kedua menggunakan rantai, dan juga terdapat tuas kontrol untuk memilih salah satu dari ketiga sproket pada poros kedua tersebut. Rangkaian ini dinamakan rangkaian transmisi rantai-sproket grup pertama $\mathrm{VR}_{1}$.

2. Pada sisi lainya dari poros kedua terdapat sebuah sproket yang dihubungkan ke sebuah sproket pada poros ketiga menggunakan rantai. Rangkaian ini dinamakan rangkaian transmisi rantai-sproket $\mathrm{VR}_{2}$.

3. Pada sisi lainya dari poros ketiga terdapat sebuah sproket yang dihubungkan ke sebuah sproket pada poros ke empat (poros alat pencetak pelet) menggunakan rantai. Rangkaian ini dinamakan rangkaian transmisi rantai-sproket $\mathrm{VR}_{3}$.

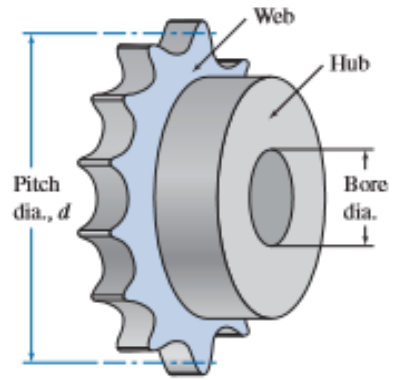

Gambar 1. Sproket (Myszka, 2012)

Penelitian ini menggunakan dua metode, yakni oberservasi dan tinjauan literatur. Metode oberservasi digunakan untuk mengumpulkan informasi aktual tentang hasil studi perbandingan antara perhitungan teoritis dan kondisi aktual ukuran sproket dan kecepatan putaran poros (rpm). Metode literatur digunakan untuk memperoleh informasi seputar tentang rumus perhitungan poros, pengukuran kecepatan putaran serta jenis peralatan yang akan digunakan untuk merancang mesin pembuat pakan pelet. Kedua metode ini memberikan informasi tentang perbandingan nilai teoritis hasil perhitungan ukuran sproket dan kecepatan putaran poros yang 
dihasilkan melalui studi perbandingan antara nilai perhitungan teoritis dan nilai aktual yang terjadi ketika dilakukan pengujian terhadap alat tersebut. Langkahlangkah penelitian dapatdilihat dalam Gambar 2.
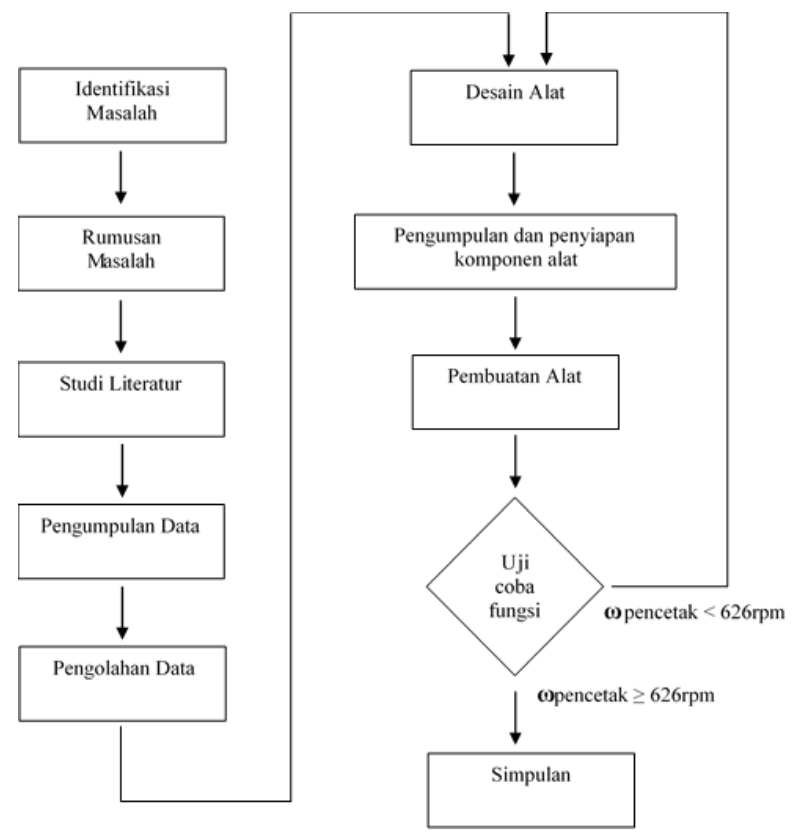

Gambar 2. Langkah-langkah penelitian

\section{Hasil dan Pembahasan}

\subsection{Data observasi}

Data sproket dan rantai yang diamati dan diukur selama dilakukannya observasi pada sepeda dengan merek Centurion Blackfire M6 adalah sebagai berikut:

1. Sproket:
a. Merk / model
:Shimano / Alivio
b. Ketebalan
: 0,125 inchi
c. Jumlah gigi $\operatorname{driver}\left(\mathrm{N}_{1}\right)$
: $24 \mathrm{~T}, 34 \mathrm{~T}, 42 \mathrm{~T}$
d. Jumlah gigi $\operatorname{driven}\left(\mathrm{N}_{2}\right)$
: $11 \mathrm{~T}, 13 \mathrm{~T}, 15 \mathrm{~T}, 18$
$\mathrm{T}, 21 \mathrm{~T}, 24 \mathrm{~T}, 28 \mathrm{~T}, 32 \mathrm{~T}$
e. Jarak antar poros sproket (C): 16,5 inchi

2. Rantai:
a. Merk / model
: Shimano CS-HG40
b. Pitch $(p)$
: 0,5 inchi
c. Panjang rantai $(\mathrm{L})$
: 108 pitch

3. Rear Derailer $(R D)$
a. Merk / model
: Shimano / Alivio
b. Jumlah gigi driver $\left(\mathrm{N}_{1}\right)$
$: 13 \mathrm{~T}$
c. Jumlah gigi driven $\left(\mathrm{N}_{2}\right)$
$: 13 \mathrm{~T}$
d. Jarak antar poros sproket (C): 3,15 inchi
e. Panjang rantai (L)
: 16 pitch
f.

Data komponen sproket dan freehub, rantai serta deraileur yang diperoleh selama observasi selain yang terdapat pada sepeda dengan merek Centurion Blackfire M6 adalah sebagai berikut:
1. Sproket dan freehub:
a. Merk / model kecepatan
b. Pitch $(p)$
c. Jumlah gigi
$18 \mathrm{~T}, 21 \mathrm{~T}, 24 \mathrm{~T}$ dan $28 \mathrm{~T}$
: Shimano / SIS 7
: 0,5 inchi
: $11 \mathrm{~T}, 13 \mathrm{~T}, 15 \mathrm{~T}$,

2. Sproket dan freehub:
a. Merk / model kecepatan
b. Pitch $(p)$
c. Jumlah gigi
: Shimano / Altus 7
: 0,5 inchi
: $13 \mathrm{~T}, 15 \mathrm{~T}, 17 \mathrm{~T}$, 20T, $23 \mathrm{~T}, 26 \mathrm{~T}$ dan $30 \mathrm{~T}$

3. Rantai:
a. Merk / model
: DTO D-30
b. Pitch $(p)$
: 0,5 inchi
c. Panjang rantai $(\mathrm{L})$
: 116 pitch

4. Rear Derailer $(R D)$
a. Merk / model
: Shimano / SIS
b. Jumlah gigi driver $\left(\mathrm{N}_{1}\right)$
$: 10 \mathrm{~T}$
c. Jumlah gigi driven $\left(\mathrm{N}_{2}\right)$
$: 10 \mathrm{~T}$
d. Jarak antar poros sproket (C) : 3 inchi
e. Panjang rantai (L)
: 12 pitch

5. Rear Derailer $(R D)$
a. Merk / model
: Aochida
b. Jumlah gigi driver $\left(\mathrm{N}_{1}\right)$
$: 10 \mathrm{~T}$
c. Jumlah gigi driven $\left(\mathrm{N}_{2}\right)$
$: 10 \mathrm{~T}$
d. Jarak antar poros sproket (C) :
e. Panjang rantai (L)
:3 inchi
: 12 pitch

Jenis poros yang digunakan oleh sepeda berdasarkan pada jenis gerakan/putaran ada dua jenis yaitu:

1. Poros diam, yaitu poros yang terdapat pada roda depan dan roda belakang yang dipasang pada rangka menggunakan mur pengunci. Pada poros ini dipasang bantalan bearing dan juga terdapat hub merupakan bagian yang bergerak. Pada hub roda belakang inilah terdapat sproket yang tersambung dengan sproket kayuhan menggunakan rantai.

2. Poros berputar/penggerak, yaitu poros yang terdapat pada kayuhan penggerak. Pada poros ini terpasang tiga buah sproket penggerak.

Alat pencetak pelet yang digunakan dalam penelitian ini adalah sebuah alat penghancur daging atau yang sering disebut dengan nama Meat Mincer, dengan spesifikasi sebagai berikut:
a. Ukuran / Model
: No. 32
b. Material
: Besi Tuang
c. Penggerak
: Engkol penggerak tangan
d. Diameter poros engkol : 0,75 inchi

\subsection{Pengolahan data sproket}

Data sproket yang telah diperoleh dari observasi selanjutnya diolah untuk mendapatkan nilai rasio gigi. Dari nilai rasio gigi sehingga diperoleh kombinasi 
Teknik, 38 (1), 2017, 52

sproket untuk mendapatkan jumlah putaran yang diperlukan oleh beban utama dari alat, yaitu pada poros alat pencetak pelet. Rumus yang digunakan untuk menghitung kecapatan putaran menggunakan rumus rasio kecepatan (Myszka, 2012).

$$
V R=\frac{\omega d \text { river }}{\omega \text { driven }}=\frac{\omega_{1}}{\omega_{2}}=\frac{d_{2}}{d_{1}}=\frac{N_{2}}{N_{1}}
$$

Dari persamaan tersebut dapat diketahui bahwa nilai rasio kecepatan, rasio diameter sproket dan rasio jumlah gigi sproket driver dan driven adalah sama nilainya.

Putaran penggerak wdriver yang digunakan sebagai acuan dalam perhitungan sebesar 60 sampai 100 rpm (Fujita dan Koizumi, 2014) dan putaran beban wdriven yang dibutuhkan beban alat pencetak pelet sebesar $626 \mathrm{rpm}$ (Leksono, 2011).

$$
\begin{aligned}
V R & =\frac{\text { wdriver }}{\text { wdriven }} \mathrm{rpm} \\
& =\frac{60}{626} \mathrm{rpmsampai} \frac{100}{626} \mathrm{rpm} \\
& =0,096 \mathrm{rpmsampai} 0.16 \mathrm{rpm}
\end{aligned}
$$

Dari perhitungan diatas, nilai rasio kecepatan VR adalah 0,096 rpm sampai dengan 0,16 rpm. Hal ini berarti bahwa rasio perbandingan kecepatan putaran pada sproket driver bernilai 0,096 kali (saat putaran driver $60 \mathrm{rpm}$ ) dari kecepatan putaran pada sproket driven sampai 0,16 kali (saat putaran driver $60 \mathrm{rpm}$ ) dari kecepatan putaran pada sproket driven. Jadi kecepatan putaran driver lebih lambat dari kecepatan putaran driven. Dari data hasil observasi jumlah gigi sproket, dapat dicari nilai rasio perbandingan jumlah gigi sproket driven dibanding gigi pada sproket penggeraknya driver, sebagai contoh perhitungannya adalah:

$$
\begin{aligned}
V R & =\frac{N_{2}}{N_{1}} \text { Teeth } \\
& =\frac{32}{24} \text { Teeth } \\
& =1,333 \text { Teeth }
\end{aligned}
$$

Dari perhitungan diatas, nilai rasio jumlah gigi sproket VR adalah 1,333Teeth. Hal ini berarti bahwa rasio perbandingan jumlah gigi antara gigi sproket driven bernilai 1,333 kali lebih banyak dari jumlah gigi pada sproket drivernya, atau bisa diartikan dengan istilah 1,333 berbanding 1 . Besarnya nilai $V R$ dari beberapa kombinasi sproket selengkapnya bisa dilihat pada Tabel 1 .
Tabel 1. Nilai rasio gigi sproket Shimano Alivio

\begin{tabular}{cccc}
\hline $\begin{array}{c}\text { Jumlah gigi } \\
\text { sproket Driven } \\
\mathbf{N}_{\mathbf{2}} \text { (Teeth) }\end{array}$ & Nilai rasio $\left(\boldsymbol{V R}=\frac{\boldsymbol{N}_{\mathbf{2}}}{\boldsymbol{N}_{\mathbf{1}}}\right)$ pada sproket Driver $\mathbf{N}_{\mathbf{1}}$ \\
& $24 \mathrm{~T}$ Teeth $)$ & \\
\hline $32 \mathrm{~T}$ & 1,333 & $34 \mathrm{~T}$ & $42 \mathrm{~T}$ \\
$28 \mathrm{~T}$ & 1,167 & 0,941 & 0,762 \\
$24 \mathrm{~T}$ & 1,000 & 0,824 & 0,667 \\
$21 \mathrm{~T}$ & 0,875 & 0,706 & 0,571 \\
$18 \mathrm{~T}$ & 0,750 & 0,529 & 0,500 \\
$15 \mathrm{~T}$ & 0,625 & 0,441 & 0,429 \\
$13 \mathrm{~T}$ & 0,542 & 0,382 & 0,357 \\
$11 \mathrm{~T}$ & 0,458 & 0,324 & 0,310 \\
\hline
\end{tabular}

Dari tabel rasio diatas dapat dilihat adanya 24 variasi nilai rasio, dan dari semuanya belum ada yang mencapai nilai sama dengan rasio putaran penggerak dengan beban sebesar 0,096 rpm (rasio gigi sproket 0,096 Teeth). Untuk menyiasatinya, digunakan beberapa kombinasi atau penggabungan beberapa rasio agar hasil akhirnya bisa minimal sama dengan rasio yang diharapkan. Untuk mencari besaran nilai rasio dari penggabungan dua atau legih grup sproket menggunakan rumus total rasio kecepatan / rasio gigi (Myszka, 2012).

$$
T V=\frac{\text { win }}{\text { wout }}=\left(V R_{1}\right) \times\left(V R_{2}\right) \times\left(V R_{3}\right) \times \ldots .
$$

Pada kelompok rasio pertama $\left(\mathrm{VR}_{1}\right)$, sproket yang digunakan sebagai sproket driver $\left(\mathrm{N}_{1}\right)$ adalah sproket dengan jumlah gigi $34 \mathrm{~T}$. Hal ini karena dari hasil pengamatan sproket inilah yang terhubung langsung dengan kayuhan. Untuk mengurangi resiko putaran beban yang berkurang saat penggerak mengalami kelelahan, maka dipilih tiga rasio dengan nilai tengah pada sproket penggerak $\left(\mathrm{N}_{1}=34\right)$ yaitu pada sproket $\mathrm{N}_{2}=18 \mathrm{~T}, 21 \mathrm{~T}$, dan $24 \mathrm{~T}$ dengan nilai rasio 0,529 Teeth, 0,618 Teeth, dan 0,706 Teeth. Ketiga rasio ini dalam rumus diatas dimasukkan dalam kelompok rasio pertama $\left(\mathrm{VR}_{1}\right)$.

Setelah diketahui nilai VR yang dibutuhkan beban sebesar 0,096 Teeth dan nilai $\mathrm{VR}_{1}$ sebesar 0,529Teeth, 0,618 Teeth, dan 0,706 Teeth, selanjutnya dicari nilai rasio ke alat pencetak menggunakan perhitungan dari rumus diatas dengan dasar perhitungan nilai rasio $\mathrm{VR}_{1}$ terkecil yaitu 0,529 Teeth.

$$
\begin{aligned}
T V & =V R_{1} \times V R_{2} \\
0,096 & =0,529 \times V R_{2} \\
V R_{2} & =\frac{0,096}{0,529} \text { Teeth } \\
& =0,181 \text { Teeth }
\end{aligned}
$$

Dari perhitungan diatas, nilai rasio jumlah gigi sproket grup kedua $\mathrm{VR}_{2}$ adalah 0,181 Teeth. Hal ini berarti bahwa rasio perbandingan jumlah gigi pada grup kedua antara gigi sproket driven bernilai 0,181 kali dari jumlah gigi pada sproket drivernya, atau bisa diartikan dengan istilah 0,181 berbanding $1(0,181: 1)$. Jadi pada 
Teknik, 38 (1), 2017, 53

grup kedua ini, jumlah gigi sproket driven lebih sedikit dari jumlah gigi sproket driver. Dari Tabel 1 masih tidak ditemukan rasio dengan nilai 0,181 , sehingga dipilih nilai $\mathrm{VR}_{2}$ dengan rasio terkecil sebesar 0,262 Teeth, yaitu pada rasio sproket dengan jumlah gigi $\mathrm{N}_{2}=11 \mathrm{~T}$ dengan $\mathrm{N}_{1}=$ $42 \mathrm{~T}$, sehingga dapat diketahui bahwa sproket ketiga dan ke empat dari alat adalah sproket dengan nilai $\mathrm{N}_{3}=42 \mathrm{~T}$ $\mathrm{N}_{4}=11 \mathrm{~T}$. Langkah selanjutnya adalah mencari nilai $\mathrm{VR}_{3}$.

$$
\begin{aligned}
T V & =V R_{1} \times V R_{2} \times V R_{3} \\
0,096 & =0,529 \times 0,262 \times V R_{3} \\
V R_{3} & =\frac{0,096}{0,529 \times 0,262} \text { Teeth } \\
V R_{3} & =\frac{0,096}{0,139} \text { Teeth } \\
& =0,696 \text { Teeth }
\end{aligned}
$$

Dari perhitungan diatas, nilai rasio jumlah gigi sproket grup ketiga $\mathrm{VR}_{3}$ adalah 0,696 Teeth. Hal ini berarti bahwa rasio perbandingan jumlah gigi pada grup kedua antara gigi sproket driven bernilai 0,696 kali dari jumlah gigi pada sproket drivernya, atau bisa diartikan dengan istilah $0, \mathrm{VR}_{3}$ berbanding $1\left(0, \mathrm{VR}_{3}: 1\right)$. Jadi grup ketiga ini, jumlah gigi sproket drivennya lebih sedikit dari jumlah gigi sproket driver.

Rasio $\mathrm{VR}_{1}$ dan $\mathrm{VR}_{2}$ sudah menggunakan $\mathrm{N}_{1}(34 \mathrm{~T}$ dan $42 \mathrm{~T}$ ), sehingga $\mathrm{N}_{1}$ yang tersisa hanya tinggal $24 \mathrm{~T}$. Dari tabel rasio 4.2 diatas, nilai rasio yang mendekati nilai $\mathrm{VR}_{3}$ dan menggunakan $\mathrm{N}_{1}(24 \mathrm{~T})$ dan $\mathrm{N}_{2}$ selain $24 \mathrm{~T}, 21$ $\mathrm{T}, 18 \mathrm{~T}$ dan $11 \mathrm{~T}$ adalah pada $\mathrm{N}_{2} 15 \mathrm{~T}$ dengan nilai rasio 0,625 Teeth, sehingga nilai $\mathrm{VR}_{3}$ yang digunakan adalah 0,625 Teeth, sehingga dapat diketahui bahwa sproket kelima dan keenam dari alat adalah sproket dengan nilai $\mathrm{N}_{5}=24 \mathrm{~T}$ dan $\mathrm{N}_{6}=15 \mathrm{~T}$. Perbandingan rasio gigi $\mathrm{VR}_{3}$ inilah yang nantinya tersambung dengan beban alat pencetak pelet.

Nilai total rasio (TV) dari ketiga jenis kombinasi nilai $\mathrm{VR}_{1}$ adalah sebagai berikut:

1. Pada $\mathrm{N}_{2}=18 \mathrm{~T}\left(\mathrm{VR}_{1}=0,529\right.$ Teeth $)$

$$
\begin{aligned}
T V & =V R_{1} \times V R_{2} \times V R_{3} \text { Teeth } \\
& =0,529 \times 0,262 \times 0,626 \text { Teeth } \\
& =0,087 \text { Teeth }
\end{aligned}
$$

2. Pada nilai $\mathrm{N}_{2}=21 \mathrm{~T}\left(\mathrm{VR}_{1}=0,618\right.$ Teeth $)$

$$
\begin{aligned}
T V & =V R_{1} \times V R_{2} \times V R_{3} T \text { eeth } \\
& =0,618 \times 0,262 \times 0,626 \text { Teeth } \\
& =0,101 \text { Teeth }
\end{aligned}
$$

3. Pada nilai $\mathrm{N}_{2}=24 \mathrm{~T}\left(\mathrm{VR}_{1}=0,706\right.$ Teeth $)$

$$
\begin{aligned}
T V & =V R_{1} \times V R_{2} \times V R_{3} T \text { eeth } \\
& =0,706 \times 0,262 \times 0,626 \text { Teeth } \\
& =0,116 \text { Teeth }
\end{aligned}
$$

Nilai total rasio gigi sproket pada saat $\mathrm{N}_{2}=18 \mathrm{~T}$ adalah 0,087 Teeth, hal ini berarti bahwa saat rasio total perbandingan gigi output berbanding gigi inputnya adalah 0,087 berbanding $1(0,087: 1)$. Hal ini juga berlaku pada saat $\mathrm{N}_{2}=21 \mathrm{~T}$ dengan perbandingan 0,101 berbanding 1 $(0,101: 1)$ dan saat $\mathrm{N}_{2}=24 \mathrm{~T}$ dengan perbandingan 0,116 berbanding $1(0,116: 1)$. Jumlah putaran penggerak yang dibutuhkan pada tiga kombinasi rasio $\mathrm{VR}_{1}$ untuk menghasilkan kecepatan putaran alat sebesar $626 \mathrm{rpm}$ adalah:

1. Pada rasio $\mathrm{VR}_{1}=0,706$ Teeth, yaitu saat sproket $\mathrm{N}_{2}$ yang digunakan adalah $24 \mathrm{~T}$, maka kecepatan putaran drivernya adalah:

$$
\begin{aligned}
\text { wdriver } & =\text { wdriven } \times V R_{1} \times V R_{2} \times V R_{3} \mathrm{rpm} \\
& =626 \times 0,706 \times 0,262 \times 0,625 \mathrm{rpm} \\
& =72,37 \mathrm{rpm} \\
& =72 \mathrm{rpm}
\end{aligned}
$$

2. Pada rasio $\mathrm{VR}_{1}=0,618$ Teeth, yaitu saat sproket $\mathrm{N}_{2}$ yang digunakan adalah $21 \mathrm{~T}$, maka kecepatan putaran drivernya adalah:

$$
\begin{aligned}
\text { wdriver } & =\text { wdriven } \times V R_{1} \times V R_{2} \times V R_{3} r p m \\
& =626 \times 0,618 \times 0,262 \times 0,625 \mathrm{rpm} \\
& =63,35 \mathrm{rpm} \\
& =63 \mathrm{rpm}
\end{aligned}
$$

3. Pada rasio $\mathrm{VR}_{1}=0,529$ Teeth, yaitu saat sproket $\mathrm{N}_{2}$ yang digunakan adalah $15 \mathrm{~T}$, maka kecepatan putaran drivernya adalah:

$$
\begin{aligned}
\text { wdriver } & =\text { wdriven } \times V R_{1} \times V R_{2} \times V R_{3} \mathrm{rpm} \\
& =626 \times 0,529 \times 0,262 \times 0,625 \mathrm{rpm} \\
& =54,23 \mathrm{rpm} \\
& =54 \mathrm{rpm}
\end{aligned}
$$

Dari perhitungan diatas dapat diketahui bahwa untuk putaran beban alat pencetak pelet $\omega$ driven sebesar 626 rpm diperlukan putaran penggerak $\omega$ driver sebesar 72 rpm saat $\mathrm{N}_{2}=24 \mathrm{~T}, 63 \mathrm{rpm}$ saat $\mathrm{N}_{2}=21 \mathrm{~T}$ dan $54 \mathrm{rpm}$ saat $\mathrm{N}_{2}=18 \mathrm{~T}$.

\subsection{Perencanaan penggerak rantai - sproket}

Dari data observasi dan perhitungan sproket, diketahui bahwa ukuran pitch (p) dari rantai yang digunakan adalah 0,5 inchi, dan sproket yang akan digunakan dalam sistem penggerak rantai-sproket alat terdiri dari gabungan tiga rasio sproket, yaitu:

1. Pada rasio pertama $\left(\mathrm{VR}_{1}\right)$ menggunakan sproket driver $_{1}\left(\mathrm{~N}_{1}\right) 34 \mathrm{~T}$ dan tiga buah sproket driven $_{1}\left(\mathrm{~N}_{2}\right)$ $24 \mathrm{~T}, 21 \mathrm{~T}$ dan $18 \mathrm{~T}$.

2. Pada rasio kedua $\left(\mathrm{VR}_{2}\right)$ menggunakan sproket driver $_{2}$ $\left(\mathrm{N}_{3}\right) 42 \mathrm{~T}$ dan sproket driven $_{2}\left(\mathrm{~N}_{4}\right) 11 \mathrm{~T}$.

3. Pada rasio ketiga $\left(\mathrm{VR}_{3}\right)$ menggunakan sproket driver $_{3}$ $\left(\mathrm{N}_{5}\right) 24 \mathrm{~T}$ dan sproket driven $_{3}\left(\mathrm{~N}_{6}\right) 15 \mathrm{~T}$.

Dari kedua data rantai dan sproket tersebut, dapat dihitung jarak titik tengah dari dua sproket driver dan sproket driven dan panjang rantainya pada setiap rasio. Sesuai dengan teori yang dikemukakan oleh Myzska (2012) bahwa jarak titik tengah (C) berkisar antara 30 sampai 50 puncak pitch(p) dari rantai yang digunakan (30p $<\mathrm{C}<50 \mathrm{p})$, maka jarak titik tengahnya (C) adalah $(30 \times 0,5)<C<(50 \times 0,5)$, atau $15<C<25$. Jadi besarnya jarak antar sproket adalah lebih dari 15 inchi tetapi kurang dari 25 inchi.

Untuk Rasio pertama jarak antar poros dibuat lebih panjang dari rasio kedua dan ketiga karena pada rasio ini 
Teknik, 38 (1), 2017, 54

terdapat 3 kombinasi yang dalam merubah kombinasi ditambahkan alat yang dikenal dengan istilah derailer dan juga terdapat kayuhan sehingga diharapkan nantinya sproket driven dan derailer tidak mengganggu dalam operasi pengayuhan. Besarnya nilai $\mathrm{C}$ dari ketiga rasio adalah sebagai berikut:

1. Pada rasio pertama sebesar 18 inchi

2. Pada rasio kedua sebesar 16 inchi

3. Pada rasio ketiga sebesar 16 inchi

Setelah jarak antar sproket sudah ditentukan, maka langkah selanjutnya dihitung panjang rantainya menggunakan rumus dari teori yang dikemukakan oleh Myszka (2012), yaitu:

$$
L=\frac{2 C}{p}+\frac{\left(N_{2}+N_{1}\right)}{2}+\left\{\frac{p\left(N_{2}+N_{1}\right)^{2}}{4 \pi^{2} C}\right\}
$$

1. Panjang rantai pada rasio pertama dihitung dengan acuan nilai $\mathrm{N}_{2}$ terbesar yaitu 24 gigi dan ditambah panjang rantai pada derailer (Shimano SIS), maka:

$$
\begin{aligned}
L_{1} & =\left[\frac{2 \times 18}{0,5}+\frac{(24+34)}{2}+\left\{\frac{0,5(24-34)^{2}}{4 \times 3,14^{2} \times 18}\right\}\right]+12 \text { pitch } \\
& =\left[\frac{36}{0,5}+\frac{58}{2}+\frac{50}{709,89}\right]+12 \text { pitch } \\
& =[72+29+0,07]+12 \text { pitch } \\
& =101,07+12 \text { pitch }=113 \text { pitch }
\end{aligned}
$$

Dalam praktiknya, jumlah pitch dari rantai selalu genap karena berpasangan, sehingga bisa digunakan 112 pitch jika dipilih setelan rantai ketat atau 114 pitch jika dipilih setelan rantai kendur. Pada alat ini digunakan rantai dengan panjang 112 pitch pada rasio pertama karena dipilih setelan rantai ketat.

2. Pada rasio kedua tidak ditambahkan derailer, sehingga panjang rantainya adalah:

$$
\begin{aligned}
L_{2} & =\frac{2 \times 16}{0,5}+\frac{(11+42)}{2}+\left\{\frac{0,5(11-42)^{2}}{4 \times 3,14^{2} \times 16}\right\} \text { pitch } \\
& =\frac{32}{0,5}+\frac{53}{2}+\left\{\frac{480,5}{631}\right\} \text { pitch } \\
& =64+26,5+0.76 \text { pitch } \\
& =91,26 \text { pitch }
\end{aligned}
$$

Pada alat ini digunakan rantai dengan panjang 90 pitch pada rasio kedua karena dipilih setelan rantai ketat.

3. Pada rasio ketiga ditambahkan derailer (Aochida), sehingga panjang rantainya adalah:

$$
\begin{aligned}
L_{3} & =\left[\frac{2 \times 16}{0,5}+\frac{(15+24)}{2}+\left\{\frac{0,5(15-24)^{2}}{4 \times 3,14^{2} \times 16}\right\}\right]+12 \text { pitch } \\
& =\left[\frac{32}{0,5}+\frac{39}{2}+\frac{40,5}{631}\right]+12 \text { pitch } \\
& =[64+19,5+0,06]+12 \text { pitch } \\
& =83,56+12 \text { pitch } \\
& =95,26 \text { pitch }
\end{aligned}
$$

Pada alat ini digunakan rantai dengan panjang 94 pitch

\begin{tabular}{|c|c|c|c|c|}
\hline No & Nama Komponen & Jumlah & Satuan & Keterangan \\
\hline 1 & Rangka dudukan alat & 1 & unit & $\begin{array}{l}\text { dibuat sendiri, dengan referensi } \\
\text { gambar 4.4. sampai } 4.7 \text {. }\end{array}$ \\
\hline 2 & Rangka sepeda & 1 & set & \\
\hline 3 & Meat Mincer & 1 & unit & model no. 32 \\
\hline 4 & Tempat duduk sepeda & 1 & set & \\
\hline 5 & Setang & 1 & set & \\
\hline 6 & Poros Kayuhan & 1 & set & \\
\hline 7 & Roda belakang komplet & 1 & set & ukuran 26 inchi \\
\hline 8 & Poros dan freehub & 2 & set & Shimano SIS dan Shimano Altus \\
\hline 9 & Sproket 11T & 1 & unit & ukuran 40 (pitch 0,5 inchi) \\
\hline 10 & Sproket $15 \mathrm{~T}$ & 1 & unit & ukuran 40 (pitch 0,5 inchi) \\
\hline 11 & Sproket $18 \mathrm{~T}, 21 \mathrm{~T}, 24 \mathrm{~T}$ & 1 & set & ukuran 40 (pitch 0,5 inchi) \\
\hline 12 & Sproket 24T & 1 & unit & ukuran 40 (pitch 0,5 inchi) \\
\hline 13 & Sproket $34 \mathrm{~T}$ & 1 & unit & ukuran 40 (pitch 0,5 inchi) \\
\hline 14 & Sproket $42 \mathrm{~T}$ & 1 & unit & ukuran 40 (pitch 0,5 inchi) \\
\hline 15 & Rantai & 112 & pitch & ukuran 40 (pitch 0,5 inchi) \\
\hline 16 & Rantai & 90 & pitch & ukuran 40 (pitch 0,5 inchi) \\
\hline 17 & Rantai & 94 & pitch & ukuran 40 (pitch 0,5 inchi) \\
\hline 18 & Deraileur & 2 & set & Shimano SIS dan Aochida \\
\hline 19 & Mur dan baut & 2 & set & $\begin{array}{l}\text { M12 x 30, untuk mengikat garpu } \\
\text { depan sepeda dengan rangka alat }\end{array}$ \\
\hline 20 & Tuas pengatur deraileur & 1 & set & \\
\hline 21 & Klem U-bolt & 2 & set & ukuran 1,5 inchi \\
\hline 22 & $\begin{array}{l}\text { Digital tachometer dan } \\
\text { sensor proximity }\end{array}$ & 2 & set & disatukan dalam 1 kotak panel \\
\hline 23 & Mur dan baut & 10 & set & $\begin{array}{l}\text { M10 x 40, untuk mengikat alat } \\
\text { pencetak dan roda castor ke rangka } \\
\text { alat }\end{array}$ \\
\hline 24 & Roda castor & 2 & unit & $\begin{array}{l}\text { dipasang pada kanan dan kiri rangka } \\
\text { alat }\end{array}$ \\
\hline
\end{tabular}
pada rasio ketiga karena dipilih setelan rantai ketat.

\subsection{Perancangan alat}

Perancangan menggunakan bantuan program gambar tiga dimensi Google Sketchup, kemudian gambar rancangan tersebut dipindahkan ke Google LayOut untuk diberi keterangan ukuran dimensi dan detail nama komponennya, dan di simpan dalam bentuk file $p d f$.

\subsection{Pengumpulan dan penyiapan komponen alat}

Setelah gambar rancangan selesai dibuat, maka langkah selanjutnya adalah pengumpulan dan penyiapan komponen dari alat yang akan dibuat sesuai dengan Tabel 2.

Tabel 2. Daftar komponen alat

\subsection{Pembuatan alat}

Setelah gambar rancangan dan penyiapan bahan dan komponen selesai dilakukan, maka langkah selanjutnya adalah pembuatan alat. Komponen dari alat yang pertama kali dibuat adalah rangka dudukan alat (Gambar 3).

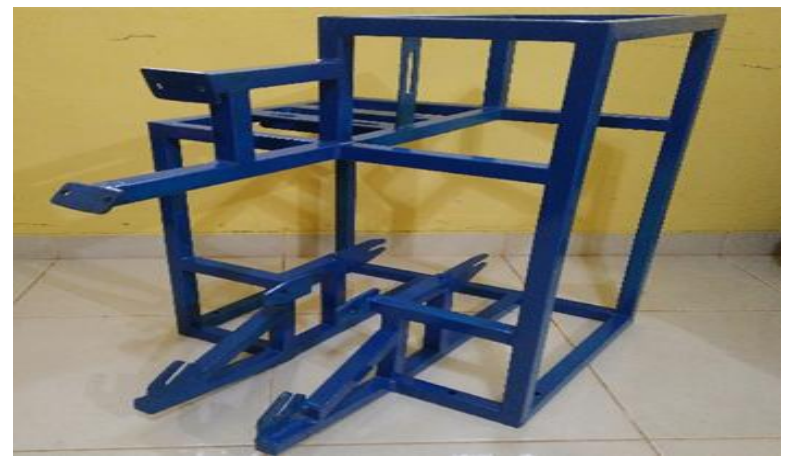

Gambar 3. Rangka dudukan alat

Setelah lapisan cat pada rangka alat kering, maka semua komponen pembentuk alat dipasang pada rangka tersebut, 
Teknik, 38 (1), 2017, 55

menggunakan acuan dari gambar rancangan yang sudah dibuat, yaitu:

1. Rangka sepeda yang sebelumnya sudah dipasang roda belakang, tempat duduk dan sproket $\mathrm{N}_{1}(34 \mathrm{~T})$ beserta poros kayuhannya dirangkai pada rangka alat menggunakan 2 (dua) set $U$-bolt pada sisi depan atas rangka dan 2 (dua) set mur dan baut pengikat pada garpu depan.

2. Dua unit roda castor dipasang pada sisi kanan dan kiri dari rangka menggunakan 4 (empat) set mur dan baut M10 x 40.

3. Poros kedua (freehub) lengkap dengan sproket $\mathrm{N}_{2}(18$ $\mathrm{T}, 21 \mathrm{~T}, 24 \mathrm{~T}$ ) dan $\mathrm{N}_{3}$ (42 T) serta deraileur (Shimano SIS) dipasang pada dudukannya di rangka alat. Setelah kedua mur pengikat di kedua sisinya dikuatkan selanjutnya dipasang rantai $(112$ pitch $)$ untuk menghubungkan sproket $\mathrm{N}_{1}$ dengan $\mathrm{N}_{2}$ melaui kedua sproket pada deraileur dan dicoba gerakan dari spoket dan rantai tersebut sampai dihasilkan putaran yang lancar.

4. Poros ketiga (freehub) lengkap dengan sproket $\mathrm{N}_{4}(11$ $\mathrm{T})$ dan $\mathrm{N}_{5}(24 \mathrm{~T})$ serta deraileur (Aochida) dipasang pada dudukannya di rangka alat. Setelah kedua mur pengikat di kedua sisinya dikuatkan selanjutnya dipasang rantai (90 pitch) untuk menghubungkan sproket $\mathrm{N}_{3}$ dengan $\mathrm{N}_{4}$ dan dicoba gerakan dari spoket dan rantai tersebut sampai dihasilkan putaran yang lancar.

5. Alat pencetak pelet, beserta sproket $\mathrm{N}_{6}\left(\begin{array}{ll}15 & \mathrm{~T}\end{array}\right)$ dipasang pada dudukannya menggunakan 4 (empat) set mur dan baut M10 x 40. Setelah terpasang dengan kuat, dipasang rantai (94 pitch) untuk menghubungkan sproket $\mathrm{N}_{5}$ dengan $\mathrm{N}_{6}$ melaui kedua sproket pada deraileur (Aochida) dan dicoba gerakan dari spoket dan rantai tersebut sampai dihasilkan putaran yang lancar.

6. Pada deraileur (Shimano SIS) dipasang kawat sling yang tersambung ke tuas pengontrol pilihan besarnya sproket $\mathrm{N}_{2}$. Tuas pengontrol tersebut dipasang pada setang sepeda.

7. Pada setang sepeda juga terdapat sebuah kotak panel yang berisi dua alat digital tachometer untuk mengetahui besarnya kecepatan putaran poros kayuhan (driver) dan poros alat pencetak (driven).

8. Sensor pembaca putaran poros kayuhan dipasang pada dudukannya yang terdapat di rangka sepeda dekat dengan poros kayuhan.

9. Sensor pembaca putaran poros alat pencetak dipasang pada dudukannya yang terdapat di rangka alat dekat dengan alat pencetak pelet (Gambar 4).

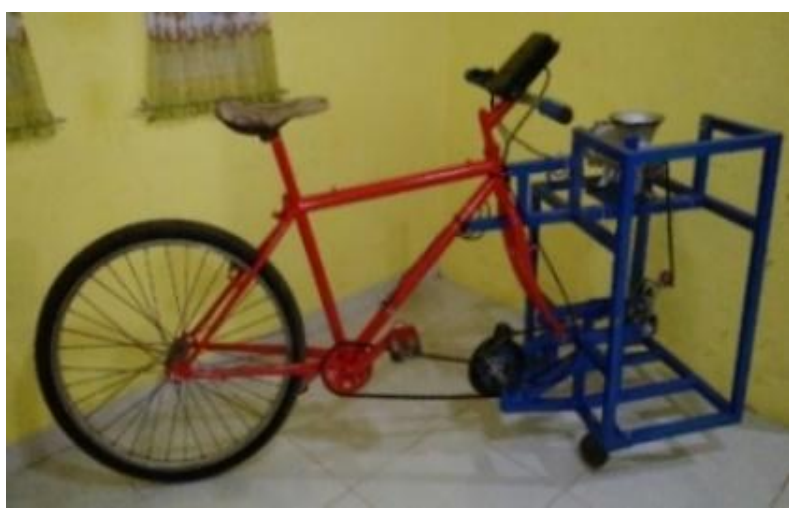

Gambar 4 .Rangkaian lengkap mesin pembuat pelet

\subsection{Pengujian alat}

Setelah semua komponen alat dirangkai, selanjutnya dilakukan pengujian untuk mengetahui bahwa alat berfungsi sesuai dengan harapan dan rancangan awal, yaitu mendapatkan kecepatan putaran akhir pada poros alat pencetak sebesar $626 \mathrm{rpm}$. Pengujian dilakukan pada ketiga kombinasi total rasio (TV), dengan nilai $\mathrm{VR}_{1}$ yang berbeda-beda, tiap kombinasi total rasio sebanyak tiga kali pengulangan, dan pada tiap pengujian dilakukan sepuluh kali pengamatan pada kondisi alat pencetak tanpa beban. Pengukuran menggunakan dua buah digital tachometer yang terpasang pada kotak yang diletakkan di setang sepeda, untuk mengukur kecepatan putaran kayuhan penggerak (driver) dan kecepatan putaran alat pencetak pelet (driven). Kemudian hasil dari pengujian tersebut diperbandingkan (Gambar 5, 6 dan 7).

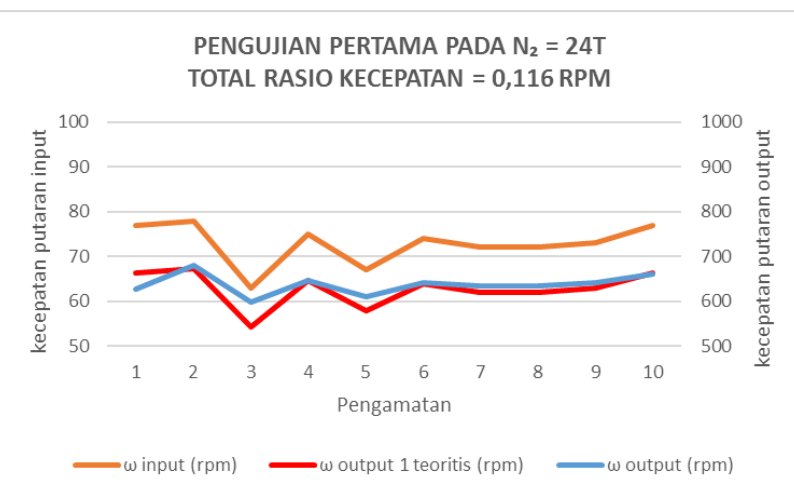

Gambar 5. Grafik perbandingan putaran output teoritis dengan aktual pengujian pertama pada $\mathrm{N}_{2}=24 \mathrm{~T}$ 


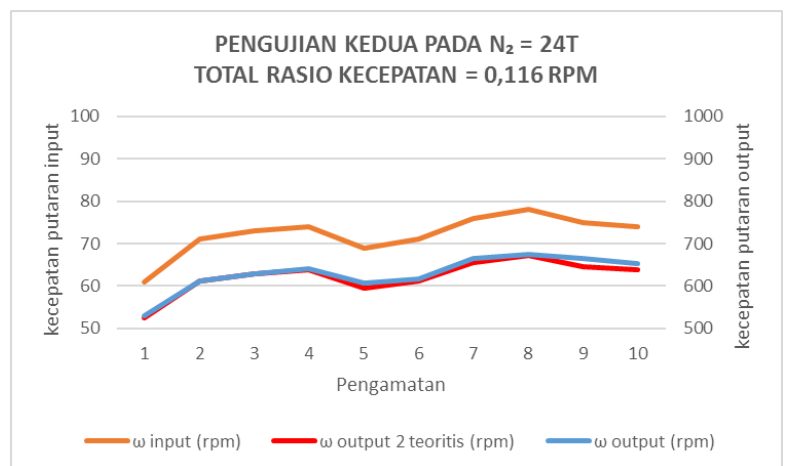

Gambar 6. Grafik perbandingan putaran output teoritis dengan aktual pengujian kedua pada $\mathrm{N}_{2}=24 \mathrm{~T}$

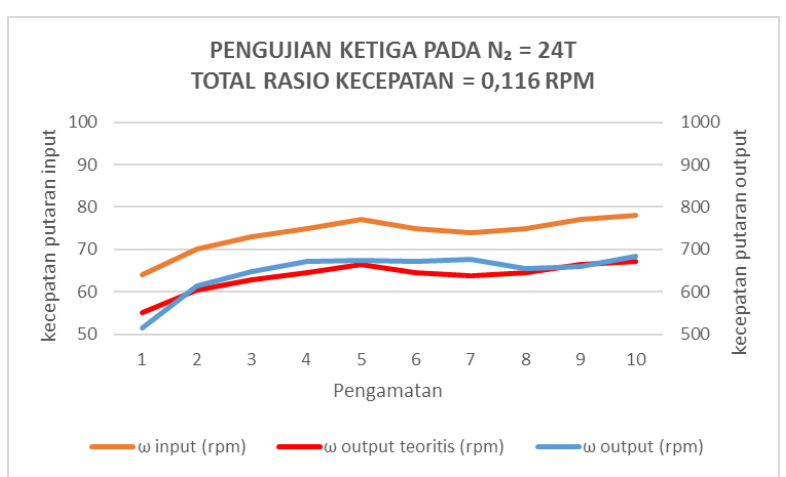

Gambar 7. Grafik perbandingan putaran output teoritis dengan aktual pengujian ketiga pada $\mathrm{N}_{2}=24 \mathrm{~T}$

(Gambar 5, Gambar 6 dan Gambar 7) menunjukkan bahwa nilai perhitungan teoritis yang telah dilakukan memiliki kedekatan dengan nilai aktualnya (kecepatan putaran). Artinya, alternatif ukuran sproket yang digunakan dalam perancangan alat pembuat pakan pelet ini mampu mencapai target pencapaian yang diharapkan yaitu sebesar $626 \mathrm{rpm}$. Beberapa pengulangan pengujian, kecepatan putaran poros bahkan dapat mencapai kecepatan sebesar $675 \mathrm{rpm}$. Kondisi ini sekaligus juga menjelaskan bahwa adanya hubungan antara besar input (gaya) terhadap output (kecepatan putaran) yang dihasilkan. Walaupun dalam beberapa pengujian, inkonsistensi kecepatan putaran masih terjadi dibeberapa pengulangan pengujian. Nilai kecepatan putaran poros dapat dilihat pada Tabel 3.

Dari hasil pengukuran pengujian alat dapat diketahui bahwa kecepatan putaran poros alat sebesar 626 rpm sudah dapat dicapai dengan kecepatan kayuhan sebesar $54 \mathrm{rpm}$ saat $\mathrm{N}_{2}=18 \mathrm{~T}, 63 \mathrm{rpm}$ saat $\mathrm{N}_{2}=21 \mathrm{~T}$, dan $72 \mathrm{rpm}$ saat $\mathrm{N}_{2}=24 \mathrm{~T}$. sedangkan besarnya ukuran sproket yang digunakan masing-masing sebesar $\mathrm{N}_{1}=34$ $\mathrm{T}$, sproket $\mathrm{N}_{2}=18 \mathrm{~T}, 21 \mathrm{~T}$ dan $24 \mathrm{~T}$, sproket $\mathrm{N}_{3}=42 \mathrm{~T}$, sproket $\mathrm{N}_{4}=11 \mathrm{~T}$, sproket $\mathrm{N}_{5}=24 \mathrm{~T}$ dan sproket $\mathrm{N}_{6}=15$ $\mathrm{T}$.
Tabel 3. Perbandingan putaran output aktual dengan teoritis pada $\mathrm{N}_{2}=24 \mathrm{~T}$

\begin{tabular}{|c|c|c|c|c|c|c|c|c|c|c|}
\hline \multirow{2}{*}{$\begin{array}{c}N_{2}=24 \mathrm{~T} \\
\mathrm{TV}=0,116 \mathrm{rpm}\end{array}$} & \multicolumn{10}{|c|}{ Pengamatan } \\
\hline & I & II & III & IV & V & VI & VII & VIII & IX & $\mathbf{X}$ \\
\hline $\begin{array}{ll} & \omega \text { input } \\
\text { Pengu- } & (\mathrm{rpm})\end{array}$ & 77 & 78 & 63 & 75 & 67 & 74 & 72 & 72 & 73 & 77 \\
\hline $\begin{array}{l}\text { jian } \\
\text { pertama }\end{array} \begin{array}{l}\omega \text { output } \\
(\mathrm{rpm})\end{array}$ & 628 & 681 & 598 & 647 & 609 & 642 & 634 & 634 & 641 & 661 \\
\hline \multirow{2}{*}{$\begin{array}{l}\text { Pengu- } \\
\text { jian } \\
\text { kedua }\end{array}$} & 1 & 71 & 73 & 74 & 69 & 71 & 76 & 78 & 75 & 74 \\
\hline & 530 & 613 & 628 & 641 & 606 & 617 & 665 & 675 & 665 & 654 \\
\hline $\begin{array}{ll}\text { Pengu- } & \begin{array}{l}\omega \text { input } \\
\text { (rpm) }\end{array} \\
\text { jian }\end{array}$ & 64 & 70 & 73 & 75 & 77 & 75 & 74 & 75 & 77 & 78 \\
\hline ketiga $\begin{array}{l}\begin{array}{l}\omega \\
\text { output } \\
(\mathrm{rpm})\end{array}\end{array}$ & 514 & 615 & 649 & 673 & 675 & 672 & 676 & 654 & 660 & 683 \\
\hline
\end{tabular}

\section{Kesimpulan}

Untuk mendapatkan kecepatan putaran poros diatas $626 \mathrm{rpm}$ maka ukuran sproket pada poros penggerak dimesin pembuat pakan pelet adalah $\mathrm{N}_{1}=34 \mathrm{~T}$, sproket $\mathrm{N}_{2}=18 \mathrm{~T}, 21 \mathrm{~T}$ dan $24 \mathrm{~T}$, sproket $\mathrm{N}_{3}=42 \mathrm{~T}$, sproket $\mathrm{N}_{4}=$ $11 \mathrm{~T}$, sproket $\mathrm{N}_{5}=24 \mathrm{~T}$ dan sproket $\mathrm{N}_{6}=15 \mathrm{~T}$. Kedepannya, penelitian ini diharapkan dapat memperluas variabel penelitian yang tidak hanya sebatas pada ukuran sproket, namun juga pada komponen lain seperti alat pemotong pakan untuk mendapatkan produk pakan yang seragam, pemisah pakan sampai pada studi kelayakan produk yang dihasilkan. Dari hasil kajian tersebut, diharapkan akan diperoleh satu produk utuh yang bukan hanya berupa hasil kajian penelitian saja, namun juga memilki nilai komersil.

\section{Ucapan Terima Kasih}

Mengucapkan terima kasih pada Program Studi Teknik Industri Universitas Putera Batam yang telah memberikan rekomendasi pendanaan penelitian dan LPPM Universitas Putera Batam yang telah mendukung pendanaan penelitian ini, serta berbagai pihak yang terlibat langsung untuk mendukung keberhasilan kegiatan penelitian ini.

\section{Daftar Pustaka}

Fujita, Y. dkk. (2014). Efficiency Variation in Cycling Exercise Related to Cadence and Work Rate Standardized by Ventilatory Threshold, International. Journal of Sport and Health Science, Vol.12, 38-46.

Garg, Vishal dkk. (2013). Design and Experimental Setup of Pedal Operated Water Pump. International Journal of Engineering Research \& Technology, 2(1).

Gehlot, Vishal, dkk. (2015). Design and Fabrication of Pedal Operated Air Compressor. International Journal of Science and Research, 4(1). 
Teknik, 38 (1), 2017, 57

Leksono, Y. K., Setiyo, Y., Tika, I W.(2014). Modifikasi Mesin Pencetak Pakan Budidaya Lele Berbentuk Pelet dengan Kebutuhan Daya Rendah. Biosistem dan Teknik Pertanian, 2(1). Diakses dari: $<$ https://ojs.unud.ac.id/index.php/beta/article/view/ $\underline{16652}>$

Muliantara, Agus (2012). Penentuan Komposisi Bahan Pakan Ikan Lele Yang Optimal Dengan Menggunakan Metode Iwo-Subtractive Clustering. Jurnal Ilmu Komputer, 5(2), 23-28.

Myszka, David H. (2012). Machines and mechanisms: applied kinematic analysis. New Jersey: Prentice Hall-Pearson Education.

Sreejith, K. dkk. (2014). Experimental Investigation of Pedal Powered Centrifugal Pump. International Journal of Engineering And Science, 4(8).
Subash, R. dkk. (2014). Fabrication of pedal powered hacksaw using dual chain drive. International Journal of Engineering \& Technology, 3(2).

Syahputra, Adrian (2010). Rancang Bangun Alat Pembuat Pakan Ikan Mas dan Ikan Lele Bentuk Pelet. Skripsi. Medan: Departemen Teknologi Pertanian Fakultas Pertanian Universitas Sumatera Utara.

Tjahjanti, Prantasi Harmi dkk (2013). Pembuatan pakan ikan dan mesin pellet untuk kelompok petani tambak lele dan ikan nila desa penatar sewu kabupaten sidoarjo. Skripsi. Sidoarjo: Teknik Mesin Universitas Muhammadiyah Sidoarjo. 